\title{
Insulin, insulin-like growth factor 1 and insulin-like growth factor binding protein 3 serum concentrations in patients with adenomatous colon polyps
}

\author{
Adam Janiak ${ }^{1}$, Piotr Oset ${ }^{2}$, Renata Talar-Wojnarowska², Anna Kumor ${ }^{3}$, Ewa Małecka-Panas² \\ ${ }^{1}$ Department of Gastrointestinal, General and Oncological Surgery, Medical University of Lodz, Poland \\ 2Department of Digestive Tract Diseases, Medical University of Lodz, Poland \\ ${ }^{3}$ Department of Pulmonology and Allergy, Medical University of Lodz, Poland
}

Prz Gastroenterol 2013; 8 (5): 308-314 DOI: $10.5114 / p g .2013 .38734$

Key words: adenomatous polyps, insulin, insulin-like growth factor 1, insulin-like growth factor binding protein 3.

Address for correspondence: Renata Talar-Wojnarowska MD, PhD, Department of Digestive Tract Diseases, Medical Univeristy of Lodz, 22 Kopcińskiego St, 90-153 Lodz, Poland, phone: +48 4267864 80, fax: 484267864 80, e-mail: r-wojnarowska@wp.pl

\begin{abstract}
Introduction: Insulin stimulates colonic mucosal cells proliferation directly and by influencing the concentration of insulin-like growth factor 1 (IGF-1) and insulin-like growth factor binding protein 3 (IGFBP-3).

Aim: To estimate serum concentrations of insulin, IGF-1, and IGFBP-3 and to determine the relationships between them and colorectal adenoma location, dysplasia grading, histological type, and size.

Material and methods: The study included 60 patients with colorectal adenomatous polyps found on colonoscopy and confirmed pathologically. The control group consisted of 30 individuals with no positive findings on colonoscopy. All patients had their blood drawn for assessment of insulin, IGF-1, and IGFBP-3 serum concentrations.

Results: One hundred and nine adenomas (6-40 mm in size) were found in 60 study patients. The average age of patients with multiple polyps was significantly higher than that of patients with single pathologies (61.1 vs. 56.7 years respectively $(p<0.05)$ ). A higher adenoma incidence rate was observed in the distal portion of the colon than the proximal one (50 vs. 10 polyps respectively $(p<0.01)$ ). Higher serum levels of IGF-1 and IGFBP-3 were found in patients with adenomatous polyps than in the control group. The average IGF-1 concentration in patients with adenomas located proximally was also significantly higher compared to those located distally $(p<0.05)$. The insulin concentration was similar in both groups and not related to clinical data of patients.

Conclusions: The results indicate the role of IGF-1 and IGFBP-3 in early carcinogenesis of the large intestine, and IGF-1 particularly in malignant transformation in the proximal part of the organ.
\end{abstract}

\section{Introduction}

Incidence rates of colorectal cancer (CRC) in Poland are 30-35 cases/100 000/year and increase by $2.5 \%$ per year. Five-year survival rates in Poland are $25 \%$ and are among the lowest in the world [1]. Adenomatous polyps are the most common precancerous conditions of the large intestine; $70-90 \%$ of CRC arise on their background. Incidence rates of adenomatous polyps are estimated at $15 \%$ among women and 25\% among men and these values increase with age [2]. The risk of malignant transformation depends on histopathological pattern, size and dysplasia grading of the adenoma $[3,4]$. It is considered that the risk of development of cancer in adenomas measuring less than $5 \mathrm{~mm}$ is $1 \%$, in those measuring $6-9 \mathrm{~mm}$ it is $5 \%$, and in adenomas measuring more than $10 \mathrm{~mm}$ it is $20 \%$. Median age at which adenomas arise is 50 years and it precedes the development of cancer by $7-10$ years $[2,5]$.

In recent years, there has been growing concern about the influence of metabolic disorders on adenoma formation and the development of colorectal cancer. In a meta-analysis presented by Larson et al., which included 15 studies and over 2.5 million people, there was found a $30 \%$ increase in the risk of CRC among people who suffer from diabetes, regardless of gender and location of polyps [6]. Convincing evidence was found that hyperinsulinaemia might play an important role in 
pathogenesis of diabetes type 2, as well as in formation of adenomatous polyps and CRC [7]. Insulin stimulates proliferation of mucous membrane cells and CRC cells directly, as well as by the influence on concentration and bioavailability of insulin-like growth factor-1 (IGF-1). Insulin also stimulates directly in vitro mitogenesis of large intestine mucous membrane regular cells and angiogenesis of tumour vessels [8-11].

Interrelations and interactions of insulin and IGF are called the insulin-IGF axis. Elements that belong to the IGF axis are: three ligands (insulin, IGF-1, IGF-2), six receptors (insulin receptors IR $\alpha$ (fetal) and IR $\beta$ (adult), IGF-1 receptor (IGF-1R), IGF-2R, IGF-1R/IR $\alpha$ hybrid, and IGF-1R/IR $\beta$ hybrid) and over seven insulin-like growth factor-binding proteins (IGFBP1-7) [12].

Insulin-like growth factor-1 is a single-chain polypeptide, which consists of 70 amino acids $50 \%$ homologous in structure to proinsulin. The gene for IGF-1 is located on chromosome 12q22-q24.1. Regulation of IGF-1 synthesis takes place in the liver in response to stimulation by growth hormone $(\mathrm{GH})$, which is produced in the pituitary gland. Meanwhile, IGF-1 reflexively inhibits growth hormone and insulin release. Insulin-like growth factor-1 exerts its biological activity on cells by binding with its specific receptor (insulin-like growth factor receptor-1 IGF-R1), which is $70 \%$ homologous to the insulin receptor and has tyrosine kinase activity. Binding with the receptor, IGF-1 initiates many changes and by tyrosine kinase activation, and afterwards by 3-phosphatidylinositol and MAP kinase activation, it leads to inactivation of the BAD protein, which encourages apoptosis. Apart from inhibiting apoptosis, IGF-1 plays an important role in regulation of growth processes, proliferation and cell transformation. Insulin-like growth factor-1 can also induce vascular endothelial growth factor (VEGF) production, which positively influences the production of blood vessels and progression of tumour development [10]. In blood $90 \%$ of IGF-1 binds with the binding protein IGFBP-3 [8].

The protein that binds insulin-like growth factor-3 (insulin-like growth factor binding protein-3 - IGFBP-3) is a single-chain polypeptide, which consists of 264 amino acids. The gene for IGFBP-3 is located on chromosome 7p14-p12. This protein is produced mainly in the liver, but also by mesenchymal cells. Its production is influenced mainly by $\mathrm{GH}$, but also by parathormone, insulin and cytokines, such as TNF- $\alpha$ and interleukin-8. The IGFBP-3, binding with IGF-1, inhibits its activity and prolongs its half-life in serum. Not only does IGFBP-3 regulate IGF-1 bioavailability, but it also has an independent inhibitory effect on cell growth and increases proliferation and apoptosis of cells [8].

Although there has been conducted extensive research confirming the importance of insulin, IGF-1 and
IGFBP-3 in the development of colorectal cancer, not much is known about their influence on early carcinogenesis of the large intestine.

\section{Aim}

The aim of our study was to assess the IGF-1, IGFBP-3 and insulin concentrations in patients with adenomatous colon polyps and find the connection between their concentrations and location, dysplasia grading, histopathological pattern, size and number of adenomatous colon polyps.

\section{Material and methods}

Sixty patients were included in this study (25 women and 35 men), aged 30-77 years (average age 58.47 \pm 8.36 ), all of whom underwent colonoscopy with polypectomy, and adenomatous colon polyps were found in histopathological examination. The control group consisted of 30 patients ( 15 women and 15 men) with no positive findings on colonoscopy. In the group of patients with adenomas there were analyzed location and size of the polyp, dysplasia grading and histopathological pattern. There were no significant differences in age, sex and body mass index (BMI) between the study group and the control group.

All patients expressed written consent to participate in the study and were informed about its aim and progress. The protocol of the study was accepted by the Bioethics Committee at the Medical University of Lodz, agreement number RNN/44/04/KE.

Detected adenomatous colon polyps were removed endoscopically and submitted for histopathological examination in the Pathomorphology Department at the Medical University of Lodz. Adenomas of the large intestine located in the caecum, ascending colon and transverse colon were defined as proximal colon polyps, whereas those located in the descending colon, sigmoid colon and rectum were classified as distal colon polyps. The term advanced colorectal adenoma concerned polyps with diameter in excess of $1 \mathrm{~cm}$ and/or including villous pattern. In all patients a blood sample was taken into a test-tube with EDTA of capacity $9 \mathrm{~mm}$. The serum, after producing a thrombus, was centrifuged, separated, frozen at $-70^{\circ} \mathrm{C}$ and stored for further determination.

Insulin, IGF-1 and IGFBP-3 assessment was done in the Department of Laboratory Diagnostics of the Medical University of Lodz. There were used such tests as: DRG Insulin ELISA Kit, DRG IGF-1 ELISA Kit and DRG IGFBP-3 ELISA Kit by DRG Instruments GmbH (Germany). They are based on the so-called heterogeneous sandwich method and are carried out in solid phase. The first step is to incubate serum containing the investigated antigen in solid phase (coated pits) with ad- 
dition of a conjugate made of mouse antibodies and biotin. A product of this reaction was a complex: solid phase-bound antibody-antigen-biotin marked antibody. After 30 min of incubation, the superfluous amount of unbound antibodies is removed by three-fold plate flushing. The next step requires addition of an enzyme (Streptavidin Peroxidase Enzyme Complex), which specifically binds with the biotin-antibodies complex, and is followed by adding enzyme substrate. This reaction produces a substance, the colour intensity of which is proportional to the amount of the antigen and is assessed by means of spectrophotometry.

\section{Statistical analysis}

Statistical analysis was carried out with Statistica 5.5PL, using the non-parametric Mann-Whitney $U$ significance test for measurable subjects, the $\chi^{2}$ (amended by Yates) test for the assessment of relations between qualitative subjects, and Pearson's $r$ correlation coefficient for the assessment of relations between measurable subjects. In all tests statistical significance was set at $p<0.05$.

\section{Results}

One hundred and nine adenomas were diagnosed altogether in the study group. A solitary adenoma was found in 36 patients, and the 24 remaining were diagnosed with 2 to 6 polyps. Multiple adenoma patients' mean age was significantly higher than in the single polyp group (61.1 vs. 56.7 years, $p<0.05$ ). In multiple adenoma patients the one staged the highest was chosen for further evaluation.

In 23 cases pathology revealed tubular, and in 37 tubulo-villous polyp structure. No villous adenomas were found in this study. In patients with tubular adenomas

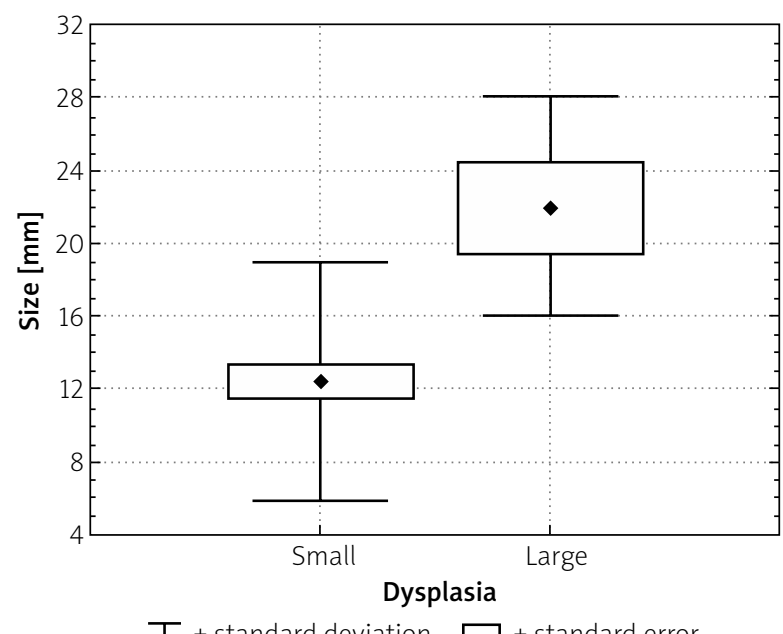

I \pm standard deviation $\square \pm$ standard error

Figure 1. Comparison of dysplasia levels with regard to polyp size $(p<0.05)$
22 had low-grade, and 1 had high-grade dysplasia. In the tubulo-villous adenoma group 32 had low-grade and 5 had high-grade dysplasia.

Statistically significantly higher incidence of distal colon adenomas (50 cases; $83.3 \%$ ) than proximal ones $(10 ; 16.7 \%)$ was observed $(p<0.01)$. In the proximal coIon 5 tubular polyps were diagnosed, each of them with low-grade dysplasia, and 5 tubulo-villous ones including 3 with low and 2 with high-grade dysplasia. In the distal colon 18 tubular polyps were found, 17 with low and 1 with high-grade dysplasia. Also, 32 tubulo-villous polyps were found in that location, of which 28 had low-grade and 4 had high-grade dysplasia. However, no correlations between adenoma location and their pathological pattern and dysplasia grading were found.

Adenoma diameters ranged from $6 \mathrm{~mm}$ to $40 \mathrm{~mm}$ (mean: $13.35 \pm 7.11 \mathrm{~mm}$ ). The mean diameter of tubulo-villous adenomas was $14.22 \pm 6.23 \mathrm{~mm}$ and was not significantly different from tubular adenoma size -11.96 $\pm 8.29 \mathrm{~mm}$ in diameter $(p<0.05)$. Thirty-nine adenomas (65\%) of a diameter less than $15 \mathrm{~mm}$ (mean $9.21 \pm 1.85 \mathrm{~mm}$ ) and 21 (35\%) of more than $15 \mathrm{~mm}$ (mean diameter of $21.05 \pm 6.85 \mathrm{~mm}$ ) were found. Statistical significance of a greater frequency of high-grade dysplasia occurrence in large adenomas (mean $22 \pm 6 \mathrm{~mm}$ ) as compared to small ones (mean diameter of $12.4 \pm 6.6 \mathrm{~mm}$ ) was established, which is illustrated in Figure 1.

A statistically significant rise in occurrence of multiple polyps was noted in patients in whom at least one adenoma was greater than $15 \mathrm{~mm}$ in diameter. There were no correlations between adenoma size, sex, age and patient BMI.

There were no differences between insulin serum concentrations in adenoma and control groups. Moreover, we found no correlation between insulin serum level and pathology pattern, dysplasia grade, size and adenoma localization (Table I).

However, a greater IGF-1 serum concentration was observed in the adenoma group $(120 \pm 33.3 \mathrm{ng} / \mathrm{ml})$ as compared to the control group (103.4 $\pm 44.91 \mathrm{ng} / \mathrm{ml})$, $p<0.05$ (Table II). Mean IGF-1 serum concentration in patients with proximal adenomas was also higher than in those with distal ones ( $p<0.05$; Table I).

Mean IGF-1 serum levels showed no difference between tubular and tubulo-villous adenoma groups. Also there were no differences between IGF-1 serum levels in patients who had non-matching pathology patterns, dysplasia levels, sizes, and localizations of adenomas. We found a statistically significant difference between IGFBP-3 serum levels in the adenoma (2808 \pm 884.89 $\mathrm{ng} / \mathrm{ml})$ and the control group (2260 $\pm 583.67 \mathrm{ng} / \mathrm{ml})$, $p<0.05$ (Figure 3). There were no dissimilarities between IGFBP-3 serum levels in patients who had dif- 
Table I. Insulin serum levels with regard to adenoma features

\begin{tabular}{|c|c|c|}
\hline Parameter & $\begin{array}{c}\text { Mean insulin level } \\
{[\mu \mathrm{IU} / \mathrm{ml}]}\end{array}$ & Value of $p$ \\
\hline Study group & $24.09 \pm 11.65$ & $>0.05$ \\
\hline Control group & $29.36 \pm 13.56$ & \\
\hline \multicolumn{2}{|l|}{ Adenomas } & \multirow{3}{*}{$>0.05$} \\
\hline Tubular & $19.64 \pm 9.5$ & \\
\hline Tubulo-villous & $20.82 \pm 12.23$ & \\
\hline \multicolumn{2}{|l|}{ Dysplasia } & \multirow{3}{*}{$>0.05$} \\
\hline Small & $20.41 \pm 11.62$ & \\
\hline Large & $19.93 \pm 6.69$ & \\
\hline \multicolumn{3}{|c|}{ Adenoma diameter [mm] } \\
\hline$<15$ & $19.48 \pm 11.12$ & \multirow[t]{2}{*}{$>0.05$} \\
\hline$>15$ & $22.07 \pm 11.36$ & \\
\hline \multicolumn{2}{|l|}{ Adenoma location } & \multirow{3}{*}{$>0.05$} \\
\hline Proximal colon & $18.19 \pm 10.94$ & \\
\hline Distal colon & $20.80 \pm 11.28$ & \\
\hline
\end{tabular}

Table II. Serum IGF-1 levels with regard to adenoma features

\begin{tabular}{|c|c|c|}
\hline Parameter & $\begin{array}{c}\text { Mean level of IGF-1 } \\
{[\mathrm{ng} / \mathrm{ml}]}\end{array}$ & Value of $p$ \\
\hline \multicolumn{2}{|l|}{ Adenomas } & \multirow{3}{*}{$>0.05$} \\
\hline Tubular & $125.9 \pm 33.88$ & \\
\hline Tubulo-villous & $116.8 \pm 32.92$ & \\
\hline \multicolumn{2}{|l|}{ Dysplasia } & \multirow{3}{*}{$>0.05$} \\
\hline Small & $120.0 \pm 32.47$ & \\
\hline Large & $120.4 \pm 43.58$ & \\
\hline \multicolumn{2}{|c|}{ Adenoma diameter [mm] } & \multirow{3}{*}{$>0.05$} \\
\hline$<15$ & $122.2 \pm 33.94$ & \\
\hline$>15$ & $116.6 \pm 3.55$ & \\
\hline \multicolumn{2}{|l|}{ Adenoma location } & \multirow{3}{*}{$<0.05$} \\
\hline Proximal colon & $143.2 \pm 21.84$ & \\
\hline Distal colon & $115.7 \pm 33.46$ & \\
\hline
\end{tabular}

ferent pathology patterns, dysplasia levels, sizes, and localizations of adenomas.

\section{Discussion}

The increase in colorectal carcinoma (CC) occurrence in Poland and worldwide as well as the high mortality rate due to this disease stimulates multiple analyses of this phenomenon. Colorectal carcinoma morbidity affects particularly developed countries as an effect of the so-called "western lifestyle". Epidemiological data presented by McKeown-Eyssen indicate that increased

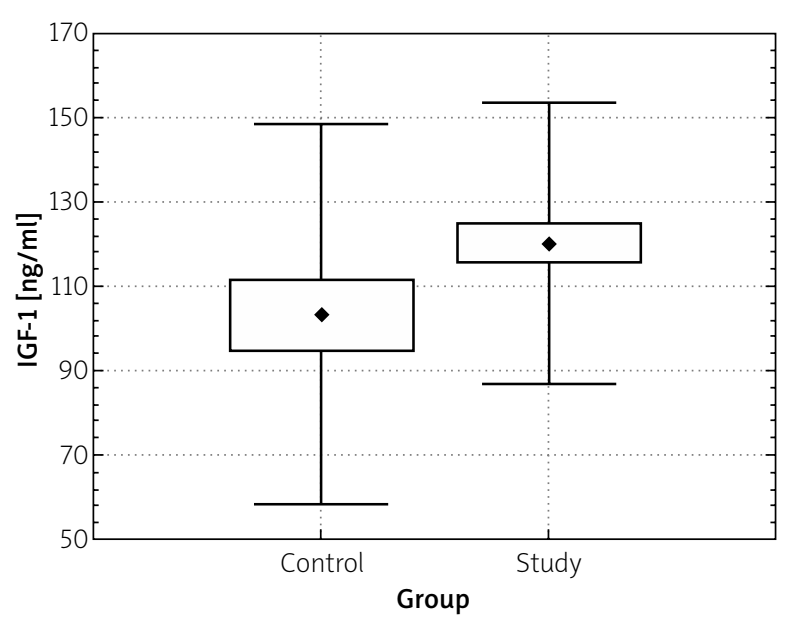

工 \pm standard deviation $\square \pm$ standard error

Figure 2. Comparison of IGF-1 in study and control group $(p<0.05)$

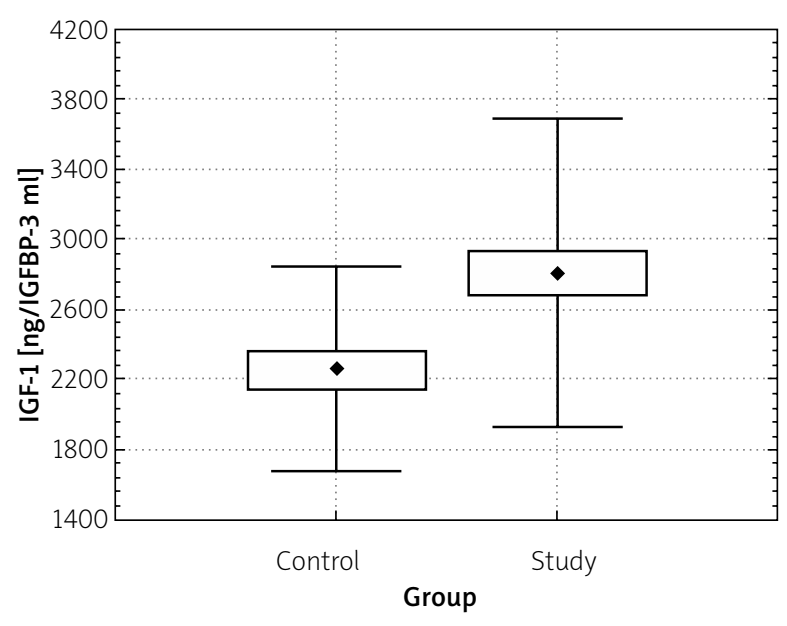

工 \pm standard deviation $\square \pm$ standard error

Figure 3. IGFBP-3 levels in study and control group $(p<0.05)$

serum levels of triglycerides and/or glucose as well as increasing colorectal carcinoma incidence may be affected by common factors arising from specific lifestyle and diet. The mechanism that encourages CC incidence in patients with increased serum triglycerides and glucose may be the increased concentration of bile acids in faeces. A rise in serum glucose levels stimulates insulin production, which in turn increases triglyceride levels secondary to hyperinsulinaemia and insulin resistance [13].

Metabolic disorders are thought to be supportive in colorectal adenoma formation, which appears to be the most frequent pre-cancerous condition of this organ. In a Polish multicenter screening study comprising 43042 colonoscopies carried out in patients aged 50 to 65, Reguła et al. revealed adenomas in 5623 (13.1\%) patients. There were 3374 (80.27\%) tubular, 998 (17.76\%) tubulo-villous, and 111 (1.97\%) villous adenomas [2]. 
Table III. Serum IGFBP-3 levels with regard to adenoma features

\begin{tabular}{|c|c|c|}
\hline Parameter & $\begin{array}{c}\text { Mean IGFBP-3 } \\
\text { concentration } \\
{[\mathrm{ng} / \mathrm{ml}]}\end{array}$ & Value of $p$ \\
\hline \multicolumn{2}{|l|}{ Adenomas } & \multirow{3}{*}{$>0.05$} \\
\hline Tubular & $2729 \pm 1046.90$ & \\
\hline Tubulo-villous & $2858 \pm 775.92$ & \\
\hline \multicolumn{2}{|l|}{ Dysplasia } & \multirow{3}{*}{$>0.05$} \\
\hline Small & $2861 \pm 880.17$ & \\
\hline Large & $2335 \pm 853.47$ & \\
\hline \multicolumn{2}{|c|}{ Adenoma diameter [mm] } & \multirow{3}{*}{$>0.05$} \\
\hline$<15$ & $2884 \pm 888.70$ & \\
\hline$>15$ & $2659 \pm 880.55$ & \\
\hline \multicolumn{2}{|l|}{ Adenoma location } & \multirow{3}{*}{$>0.05$} \\
\hline Proximal colon & $2837 \pm 883.55$ & \\
\hline Distal colon & $2802 \pm 894.18$ & \\
\hline
\end{tabular}

On the other hand, Rickert et al. investigated the occurrence of adenomas in 518 autopsies. Adenomas were found in 243 (46\%) corpses, including 94.685 tubular, $2.43 \%$ tubulo-villous, and $2.89 \%$ carcinomas. Similarly to our study, there were no villous adenomas revealed. Mean tubular adenoma diameter was $5.8 \mathrm{~mm}$, and tubulo-villous was $19.0 \mathrm{~mm}$. In this study $66.5 \%$ of tubular and $62.5 \%$ of tubulo-villous adenomas were located in the proximal colon, and respectively $33.5 \%$ and $37.5 \%$ of them distally [3]. Differences between Rickert's and our study regarding the incidence of tubular and tubulo-villous polyps and their localization may be explained by variable adenoma size and age heterogeneity of study groups.

In our study there were no differences in insulin levels between adenoma and control groups. The relationship between insulin level and colorectal adenoma and cancer formation is widely discussed. As in this study, Schoen et al. did not find any differences in fasting insulin levels between adenoma and non-adenoma patients [14]. Also Palmquist et al., as well as Saydah, did not confirm any relations between colorectal carcinogenesis and fasting serum insulin levels $[15,16]$.

However, Keku et al. observed an increased fasting insulin concentration, which was linked, especially in women, to colorectal adenoma risk increase. Apoptosis in normal mucosa was also assessed in this study, based upon morphological features such as cell shrinkage, chromatin condensation, and apoptotic body formation. A decrease in apoptosis intensity was also observed in patients with increased fasting insulin levels [17].

Flood et al. observed a 50\% increase in recurrent adenoma occurrence in the $4^{\text {th }}$ year of the Polyp Preven- tion Trial in patients with high fasting levels of insulin and glucose. A 2.43-fold increase of advanced adenoma incidence was observed in patients with fasting glucose levels higher than 99 mg\% [18]. In contrast, Miscigan et al. observed a decrease in adenoma recurrence risk in 153 patients with high fasting levels of insulin [19].

Ma et al. showed that increased insulin and C-peptide levels may predict higher risk of colorectal carcinoma in males, regardless of BMI and other insulin resistance indicators [20], which was confirmed in an experimental model. Tran et al. showed in an animal model that hyperinsulinaemia is responsible for the increase of large intestine colonic mucosal cells, administering glucose, insulin and Intralipid. Hyperinsulinaemia levels were parallel to those in insulin resistance. The authors suggest that it is hyperinsulinaemia, and not insulin resistance, that is responsible for increased CRC risk [21].

In our study we revealed increased IGF-1 serum levels in patients with adenomatous colonic polyps. Moreover, we observed significantly higher IGF-1 serum concentrations in patients with proximal colon compared to distal localization. Similarly, Giovannucchi et al. disclosed the relationship between increased IGF-1 serum levels and increased risk of advanced adenomas in the Nurses' Health Study. No correlation was noted in the case of tubular adenomas and small ones, with a diameter less than $1 \mathrm{~cm}$ [22].

The majority of authors confirm the relationship between IGF-1 serum level increase and colonic adenoma risk [14, 23-25] as well as colorectal cancer [26-29]. Jenkins et al. described acromegaly patients in whom 2 colonoscopies were performed. During the first examination there were colorectal polyps diagnosed and removed in 66 of them. On control examination, carried out at a mean of 32.7 months after the previous exploration, adenomas were re-diagnosed in $14 \%$, and in $27 \%$ hyperplastic polyps were found. Patients in whom investigators found polyps on second examination had increased levels of serum IGF-1 [23]. On the other hand, Renehan et al. described equal IGF-1 serum levels in small adenoma and non-adenoma patients. At the same time, IGF-1 serum levels were higher in the advanced adenoma group as compared to adenoma-free individuals [24].

Primarily acromegaly patients in whom there were increased levels of growth hormone as well as IGF-1 were focused upon with regard to IGF-1 levels [30]. It is widely known that in colorectal carcinoma increased expression of IGF-1R receptor is observed, and its blockage by means of monoclonal antibodies suppresses proliferation [31, 32]. In other studies the relationship between serum IGF-1 levels and CRC development in patients without previously diagnosed metabolic disorders were 
investigated. In a prospective study by Ma et al., carried out on 22071 healthy males aged 40-84, the authors concluded that a rise in serum levels of IGF-1 was associated with increased CRC risk [26]. Similar results were obtained in Greek and Swedish studies [27, 28].

On the other hand, Teramukai et al. observed no increase of IGF-1 serum concentration in patients with CRC as compared to the control group, in the case of both advanced and non-advanced adenomas [33]. Similarly, Keku et al. did not find any correlations between serum IGF-1 levels and colorectal adenoma incidence and colonic mucosal apoptosis intensification [17].

Also studies describing the role of IGFBP-3 in colonic carcinogenesis are non-coherent. Parallel to our results, Schoen et al. revealed higher serum IGFBP-3 concentrations in patients with advanced colorectal adenomas than in the control group [14]. Some authors observed no statistically significant differences in IGFBP-3 between adenoma and non-adenoma patients regardless of the level of advancement [17, 25, 33]. On the other hand, Renehan et al. described similar IGFBP-3 levels in non-advanced adenoma and non-adenoma patients. Yet in the advanced adenoma group IGFBP-3 serum levels were statistically lower than in the control group [24]. Similarly, low serum levels of IGFBP-3 were linked to increased risk of adenomas larger than $1 \mathrm{~cm}$ in diameter or villous, and not in smaller ones, as described in outcomes of the Nurses' Health Study [22].

The relationship between serum level of IGFBP-3 and $C R C$ risk remains unclear. In a prospective study, Ma et al. revealed that decreased IGFBP-3 serum levels were linked to an increased CRC risk [26]. Palmquist et al. observed increased risk of CRC that accompanied increase in serum IGFBP-3 levels. At the same time, they noted a unique trend towards decrease of CRC risk in patients with high levels of IGFBP-3, although they did not confirm it in statistical analysis [27]. The results mentioned above indicate a burning need of further large cohort studies on the role of IGFBP-3 in CRC.

Summing up, the obtained results suggest the association of IGF-1 and IGFBP-3 levels with the development of CRC. IGF-1 seems to especially affect malignant transformation in the proximal colon. Increased serum levels of these proteins were not however related either to polyp size or to dysplasia level or histopathological pattern. Undoubtedly, the observed abnormalities require further studies which may reveal mechanisms of concentration increase as well as the role of IGF-1 and IGFBP-3 in colonic carcinogenesis.

\section{Acknowledgments}

The work was supported by the Polish Society for the Prevention of Digestive Tract Neoplasms.

\section{References}

1. Karachadzis K, Paradowski L. Aktualna sytuacja epidemiologiczna nowotworów jelita grubego w Polsce [Polish]. Gastroenterol Pol 2012; 19: 64-9.

2. Reguła J, Rupinski M, Kraszewska E, et al. Colonoscopy in colorectal-cancer screening for detection of advanced neoplasia. N Engl J Med 2006; 355: 1863-72.

3. Rickert RR, Auerbach O, Garfinkel L, et al. Adenomatous lesions of the large bowel: an autopsy survey. Cancer 1979; 43: 1847-57.

4. O'Shaughnessy JA, Kelloff GJ, Gordon GB, et al. Treatment and prevention of intraepithelial neoplasia: an important target for accelerated new agent development. Clin Cancer Res 2002; 8: 314-46.

5. Gupta AK, Melton LJ 3rd, Petersen GM, et al. Changing trends in the incidence, stage, survival, and screen-detection of colorectal cancer: a population-based study. Clin Gastroenterol Hepatol 2005; 3: 150-8.

6. Larsson SC, Orsini N, Wolk A. Diabetes mellitus and risk of colorectal cancer: a meta-analysis. J Natl Cancer Inst 2005; 97 : 1679-87.

7. Gajecki D, Kempiński R, Poniewierka E. Prevalence of colonic adenomas in patients with metabolic syndrome. Prz Gastroenterol 2012; 7: 161-5.

8. Pavelić J, Matijević T, Knezević J. Biological and physiological aspects of action of insulin-like growth factor peptide family. Indian J Med Res 2007; 125: 511-22.

9. Giovannucci E. Insulin and colon cancer. Cancer Causes Control 1995; 6: 164-79.

10. Komninou D, Ayonote A, Richie JP Jr, Rigas B. Insulin resistance and its contribution to colon carcinogenesis. Exp Biol Med (Maywood) 2003; 228: 396-405.

11. Kaczka A, Kumor A, Pietruczuk M, Małecka-Panas E. Serum concentrations of insulin, insulin-like growth factor I, vascular endothelial growth factor and gastrin in patients with colon adenomas and colorectal cancer. Prz Gastroenterol 2012; 7: 216-22.

12. Sridhar SS, Goodwin PJ. Insulin-insulin-like growth factor axis and colon cancer. J Clin Oncol 2009; 27: 165-7.

13. McKeown-Eyssen G. Epidemiology of colorectal cancer revisited: are serum triglycerides and/or plasma glucose associated with risk? Cancer Epidemiol Biomarkers Prev 1994; 3: 687-95.

14. Schoen RE, Weissfeld JL, Kuller LH, et al. Insulin-like growth factor-I and insulin are associated with the presence and advancement of adenomatous polyps. Gastroenterology 2005; 129: 464-75.

15. Saydah SH, Platz EA, Rifai N, et al. Association of markers of insulin and glucose control with subsequent colorectal cancer risk. Cancer Epidemiol Biomarkers Prev 2003; 12: 412-8.

16. Palmqvist R, Stattin P, Rinaldi S, et al. Plasma insulin, IGF-binding proteins-1 and -2 and risk of colorectal cancer: a prospective study in northern Sweden. Int J Cancer 2003; 107: 89-93.

17. Keku TO, Lund PK, Galanko J, et al. Insulin resistance, apoptosis, and colorectal adenoma risk. Cancer Epidemiol Biomarkers Prev 2005; 14: 2076-81.

18. Flood A, Mai V, Pfeiffer R, et al. Elevated serum concentrations of insulin and glucose increase risk of recurrent colorectal adenomas. Gastroenterology 2007; 133: 1423-9.

19. Misciagna G, De Michele G, Guerra V, et al. Serum fructosamine and colorectal adenomas. Eur J Epidemiol 2004; 19: 425-32. 
20. Ma J, Giovannucci E, Pollak M, et al. A prospective study of plasma C-peptide and colorectal cancer risk in men. J Natl Cancer Inst 2004; 96: 546-53.

21. Tran TT, Naigamwalla D, Oprescu Al, et al. Hyperinsulinemia, but not other factors associated with insulin resistance, acutely enhances colorectal epithelial proliferation in vivo. Endocrinology 2006; 147: 1830-7.

22. Giovannucci E, Pollak MN, Platz EA, et al. A prospective study of plasma insulin-like growth factor-1 and binding protein-3 and risk of colorectal neoplasia in women. Cancer Epidemiol Biomark Prev 200; 9: 345-9.

23. Jenkins PJ, Frajese V, Jones AM, et al. Insulin-like growth factor I and the development of colorectal neoplasia in acromegaly. J Clin Endocrinol Metab 2000; 85: 3218-21.

24. Renehan AG, Painter JE, Atkin WS, et al. High-risk colorectal adenomas and serum insulin-like growth factors. Br J Surg 2001; 88: 107-13.

25. Jacobs ET, Martínez ME, Alberts DS, et al. Plasma insulin-like growth factor I is inversely associated with colorectal adenoma recurrence: a novel hypothesis. Cancer Epidemiol Biomarkers Prev 2008; 17: 300-5.

26. Ma J, Pollak MN, Giovannucci E, et al. Prospective study of colorectal cancer risk in men and plasma levels of insulin-like growth factor (IGF)-I and IGF-binding protein-3. J Natl Cancer Inst 1999; 91: 620-5.

27. Palmqvist R, Hallmans G, Rinaldi S, et al. Plasma insulin-like growth factor 1 , insulin-like growth factor binding protein 3 , and risk of colorectal cancer: a prospective study in northern Sweden. Gut 2002; 50: 642-6.

28. Manousos O, Souglakos J, Bosetti C, et al. IGF-I and IGF-II in relation to colorectal cancer. Int J Cancer 1999; 83: 15-7.

29. Kaaks R, Toniolo P, Akhmedkhanov A, et al. Serum C-peptide, insulin-like growth factor (IGF)-I, IGF-binding proteins, and colorectal cancer risk in women. J Natl Cancer Inst 2000; 92: 1592-600.

30. Renehan AG, Brennan BM. Acromegaly, growth hormone and cancer risk. Best Pract Res Clin Endocrinol Metab 2008; 22 639-57.

31. Reinmuth N, Liu W, Fan F, et al. Blockade of insulin-like growth factor I receptor function inhibits growth and angiogenesis of colon cancer. Clin Cancer Res 2002; 8: 3259-69.

32. Lahm H, Amstad P, Wyniger J, et al. Blockade of the insulin-like growth-factor-I receptor inhibits growth of human colorectal cancer cells: evidence of a functional IGF-II-mediated autocrine loop. Int J Cancer 1994; 58: 452-9.

33. Teramukai $\mathrm{S}$, Rohan T, Lee KY, et al. Insulin-like growth factor (IGF)-I, IGF-binding protein-3 and colorectal adenomas in Japanese men. Jpn J Cancer Res 2002; 93: 1187-94.

Received: 7. 12.2012

Accepted: 19.03 .2013 